\title{
Correction to: Substituted Co(II) and Cu(II) metallophthalocyanines from new Schiff base containing pyrrole units: Synthesis, characterization and investigation of photocatalytic activity on 2,3-dichlorophenol oxidation
}

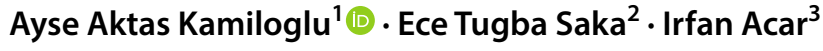

Published online: 13 November 2019

(C) Springer Nature B.V. 2019

\section{Correction to: \\ Journal of Inclusion Phenomena and Macrocyclic Chemistry \\ https://doi.org/10.1007/s10847-019-00949-z}

The article "Substituted $\mathrm{Co}(\mathrm{II})$ and $\mathrm{Cu}(\mathrm{II})$ metallophthalocyanines from new Schif base containing pyrrole units: Synthesis, characterization and investigation of photocatalytic activity on 2,3 dichlorophenol oxidation" written by "Ayse Aktas Kamiloglu, Ece Tugba Saka and Irfan Acar", was originally published electronically on the publisher's internet portal (currently SpringerLink) on 18 October 2019 with open access.

With the author(s)' decision to step back from Open Choice, the copyright of the article changed on 13 November 2019 to $\odot$ Springer Nature B.V. 2019 and the article is forthwith distributed under the terms of copyright.

The original article has been corrected.

Publisher's Note Springer Nature remains neutral with regard to jurisdictional claims in published maps and institutional affiliations.
The original article can be found online at https://doi.org/10.1007/ s10847-019-00949-z.

\section{Ayse Aktas Kamiloglu}

ayse_aktas_kamiloglu@artvin.edu.tr;

ayse_aktas@hotmail.com

1 Artvin Vocational School, Artvin Çoruh University, 08100 Artvin, Turkey

2 Department of Chemistry, Faculty of Science, Karadeniz Technical University, 61080 Trabzon, Turkey

3 Department of Energy Systems Engineering, Faculty of Technology, Karadeniz Technical University, 61830 Trabzon, Turkey 